\title{
How Economic Society Impacts Medical Purpose in China
}

\author{
Jinguo Wang \\ Department of Urology \\ The First Hospital of Jilin University \\ Changchun, China \\ wangjinguolily@163.com
}

\author{
Na Wang* (corresponding author) \\ Department of Anesthesiology \\ The First Hospital of Jilin University \\ Changchun, China \\ wangna080613@163.com
}

\begin{abstract}
In recent years, with the globalization into China, the boundary of culture is becoming more broad and even more uncertain. The rise of consumer culture fundamentally changed the people's cultural viewpoints. Even so, the poor can't be abandoned their rights of basic medical care. The society with its maximum capacity should meet the most basic medical needs of all the people. We use the related literature and the current status of our society to discuss how important it is not to change our primary medical purpose.
\end{abstract}

Keywords-economic society; medical purpose; China; basic medical care

\section{INTRODUCTION}

As early as in 1970, Jean Baudrillard wrote the book "consumer society", he has open points. Today, we are surrounded by consumption and material rich in sight everywhere, this is the physical objects, services, and the mass production of goods. It now constitutes the fundamental change of human ecology. Strictly speaking, the rich people no longer surrounded by other people, because of dealing with those people has become the past, and surrounded by material goods. They are not with their friends or partners in regular trading, but from a statistical sense, due to encourage consumption rise certain functions, they often spend energy capture and manipulation of goods and information". This suggests that an obvious feature of postmodern consumer society, people have more and more about by commodity, consumption of goods and information exchanges with other often dominate people's life [1]. So life of postmodern consumer society, people care about is not how to maintain at least daily life, but how to enjoy life more comfortable, or "aesthetic". An important feature of postmodern culture lies in its consumer, so does necessarily mean lost all the aesthetic characteristics of the postmodern culture.

\section{CONSUMER SOCIETY AND POSTMODERN CONSUMER SOCIETY}

On the contrary, in the modern society, especially since the beginning of this era of globalization, people's material life is greatly becomes rich and colorful, which makes them not only in the very great degree depends on the material and cultural production, and more advocate to enjoy these substances, and consumption. If, in the modern age, people's aesthetic idea to pay attention to cultural products in production and practical, so in the modern society, people's aesthetic view, more reflect on the packaging, and consumption of cultural products. Why medical purpose in today's so everyone's attention? This is from the current medical purpose and the situation of the face. The overall goal of the current medical and past a long time, people are not so far apart. But now medical specific goal is on the "three rates", namely the incidence, mortality, life expectancy rate per person. Incidence of as little as possible, the death rate is lower, the better, life as long as possible, and to be an indicator to measure health work achievement. For example the concise encyclopedia in each country's health work is introduced, and emphasis on mortality, life expectancy, the national average has a number of doctors and beds and other indicators. It was right, of course, these indicators indeed reflect a country the level of health work.

\section{A. Health work achievement associated with economic development}

It seems, from the whole situation faced by the current, the health work target mainly concentrated on the "three rates", put the main objects of health work in "disease" and "patient", there are some drawbacks, need to study and adjust. Said the cover is not negative. In such a period of high inflation, consumer demand which country either, as long as devoted to the social reform and economic development will inevitably encounter the sacred value of the loss of "evil spirit", and function of generalization and highlights the principle of efficiency. It is the consequence that vulgar means to an end and the relationship between the objective itself completely from the purely utilitarian considerations, namely whether just to benefit others, rather than from the highest value purpose of human existence consideration and decide how to go to the action, it is defined by Max weber "formal rationality" and "substantial rationality". Weber, found that the contradiction of modern society from the relationship between these two kinds of rational and factoid-mad interpretation, form of rationality and irrationality in essence is the essential feature of modern society. Modern society, including the contemporary western society and our country's current period of a tragedy is: in the person's way of thinking and the process of social relations, the function efficiency of the originally belong to means as a goal to pursue, although the efficiency [2]. 


\section{B. Spiritual and ethical crisis}

Weber's both rational, that is, instrumental rationality (Zweckrationalitat. Instrumental rationality) and the value rationality often is in a state of nervous. If society tends to use the most effective means to achieve a purpose, can make the person extremely utilitarian or be a slave to money, because "tool" will never be the one of meaning and purpose. And "value rationality" is based on the value of the we think reasonable and the method to achieve the activities of the fair value, the rationality of moral, religious, the pursuit of beauty should be unconditional. But the tool rationality in the development of society, especially the rapid development of regional economic is not mature, tend to stifle the development of value rationality, sometimes cause atrophy, moral decline, relationship between abortion, if there is no a sound and perfect legal system and effective management mechanism, the future is difficult to envision.

\section{1) Spiritual crisis}

Formal rationality is according to actual needs and specific interests, it is in fact a causal relationship between different judgment; and the substantial rationality only the nature of value, it is about between different value logic [3].

Form rationality is objective, it always means, degree of calculation, and the rationality of the substantial rationality is subjective, it is on the purpose and the value of the consequences, it focuses on the action of ultimate meaning and responsibility of human common interests." From a purely, objective can be calculated to action in the form of perspective, weber's thought, science, technology, capitalism and the modern legal system and the administrative (bureaucracy) is highly rationality. But this kind of rationality is the pure form with substantial rationality that is seen from the essence of a special purpose significance of rationality, belief or value commitment in a can never eliminate tension between relationship." since the dawn of the modern society, with the rapid advance of social modernization, the spirit of "lost" the spirit of "pleasure" is more and more become a high-profile topic.

\section{2) Ethical crisis}

Philosopher Heidegger said: the essence of the new era is by the hand, determined by the god and the gods vanished from the earth, the earth into a "lost planet", and people have been uprooted from the land ", lost its "spiritual home". Initially started some civilization finally holy land with the land desertification and vanish in history. In the second stage, with advanced machinery industry, chemical industry, air pollution, water pollution, noise pollution, modern war, the traffic accident causes directly to the human body damage [4]. On the third stage, the first and second stages of the survival crisis continues to spread, with new threats and volume soil, with the integrated circuit, the development of laser cable, biological engineering, computer, TV, computer, robot, karaoke, MTV, recreation, test-tube baby, artificial organs, such as microelectronics, biochemical products are rolling into people with life, often at the same time, the "materialization". "Generalization", "the simplification" and "shallow", the loss of "meaning", the loss of "depth" and "the loss of moral", "the loss of history", "the loss of skills", "the loss of the ability to love", "the loss of aesthetic creation ability" are in the same profit increase. Advanced science and technology is in its great power to infiltrate human individual emotion and spirit, cause human survival crisis again and again. This crisis for the third time, it is revered as the golden rule in the traditional society "to help the poor" simple justice law, gradually by people doubt in such a materialistic era, people's social J righteousness concept gradually be materialistic erosion, materialistic replace the value of all the other as today it is widely believed in the "to" law of, become a kind of people, the purpose of the pursuit of value, if a materialistic society become a people, the purpose of common pursuit of value, what hope is there that this society, people in such a society to cover each other in order to get their own interests, the law of the jungle, lead to the poor poorer, the rich get richer [5].

\section{The influence of medical disputes}

Medicine is a complex science and there are too many uncertainties and risks. In medical treatment activity, patients of poor results due to the natural outcome of the disease itself or medical personnel negligence causation judgment is difficult. The current lack of efficient fact finds mechanism of mediation. Medical accident appraisal could have a better solution to this problem, but the medical accident appraisal is time-consuming, neutrality is poor, make conciliation efficiency can not be improved. Much of it is less than patients with expectations of efficient administrative mediation. Political mediation lack of efficient discovery mechanism and the responsibility, the administrative conciliation efficiency is not high.

\section{1) Cause of medical dispute}

Medical dispute is due to the patients and their families and medical units in the process of clinical nursing of adverse consequences and the causes of disputes caused by inconsistent. First, the characteristics of medical disputes are the cognizance of facts and responsibility. When appear harmful consequences, the hospital may be the natural outcome because of the limit or disease and is not liable. May also be because of their negligence and bear the adverse consequences. About this fact and responsibility that requires professional judgment. Able to make professional judgment may involve issues of interest and industry protection makes the patient couldn't completely trust evaluation personnel appraisal conclusion. Secondly, the medical dispute often involves the right to health and personal rights, when pay large sums of money to meet expectations, patients and their families to make some irrational behavior. Compared with other disputes, medical disputes often show the complexity of solving and more confrontational.

\section{2) Civil litigation}

Civil litigation is refers to the country to protect the civil rights and interests of citizens, legal persons and other organizations, beyond the parties and the parties to all the participants in the proceedings, the people's court in accordance with the law and to solve a civil strife and enforcement activities of binding legal documents. Civil litigation has the following characteristics: first, the public nature of the force. Compared with other ways to settle disputes, it is the national judicial power intervention, to resolve civil disputes through judicial procedures. Second, civil litigation has the strict normative. Civil activities must be 
conducted in strict accordance with the civil substantive law and procedural law. Third, civil litigation has distinct stages. Civil litigation is the activity of advance in stages. Divided into the trial stage, the prosecution stage, the court declared preparation stage, production and phase. For the whole civil litigation activities are divided into first and second instance, execution, and trial supervision.

\section{3) Impact of civil litigation and medical dispute}

Medical dispute lawsuit as civil litigation generally divided into three kinds of cause of action: the medical damage compensation disputes, medical malpractice compensation disputes, the medical service contract disputes. The characteristics of the medical dispute lawsuit mainly present now is that the case number growth, but relative to the amount of medical disputes is slightly down. Case applicable law aspect, there is a law applies not unified, the verdict gap is big. Case in the settlement, judgment or decision for the ratio is higher than the mediation. Litigation of bid also has a tendency to rise sharply. The vast majority of cases the parties have a lawyer to participate in, closing time is long, the average medical dispute lawsuit time in more than one year.

\section{The insistence of medical purpose}

About the widening gap between the phenomenon, there is a parable of the image, the idea to climb mount Everest, the two teams in Europe and the us national team in two thousand three hundred time, we only take decades [6]. Although it's a metaphor, but it's profoundly reveals the problems in our society, namely the neglect or even forget to disadvantaged groups. Especially in the field of medical and health care, a consistent in medicine since ancient times "saving", "to help the poor" and so on is worth our using for reference of law gradually been engulfed by contemporary ideas of utilitarianism, show people the medical picture now is this: one side is the person who look down on disease because can't afford the high medical costs by cold shut out of the hospital, but on the other side is rich with a lot of money to cure the disease of "hospital" should be some unwarranted change character of surgery [7]. In the final analysis, is medical purposes have taken place in a certain degree of deviation, or say "alienation". Here I borrow cover is Marx's theory about the understanding of "alienation", in philosophy, in the context of the dissimilation refers to the subject to a certain stage of development, because of their activities and produce their own opposite, and the opposite into external alien force, and go against the body itself. Projected into the medical field, also can saying is "medical" alienation, namely medical from the date of birth, its purpose is very pure, is mainly for the sick person to treat disease [8].

Doctors do not consider between the rich and the poor. But with the development of the medicine then, especially under the impact of the market economy, the medicine gradually evolved into little tool, become a kind of alienation of power for most people. Just mentioned above are the minimum requirements, also known as a person as the basic rights of people, there is some damage in health and life, access to social security and relief is indispensable. People the most basic rights including respect for their life, physical and mental integrity and their health. Only after the practical guarantee in people's life and health, people can talk about property rights and the right to development, etc. [9]. As a result, the medical problem about the livelihood of the people to the market, although greatly alleviate the burden of government, but contrary to what the government is, has been the hope that everyone needs in these health care the introduction of market factors, can be in the market competition to lower the price of services and medicines, improve the service level of the medical staff, but the results of his reforms are in the opposite situation.

Because of health problem is everyone may face special problems, pure market regulation besides market inherent defect, can't solve the problem. Life and death decisions, "the past" market model for health care to his own opinion to the disadvantages, early has always been known is free of the United States does not also in reforming health care. It enhances the government's control power and maintains social fair and justice.

\section{CONCLUSIONS}

Therefore, especially in such a society, just have been analysis, since it is everyone's forces staggered together to form resultant force to promote the development of the society, so social is supposed to safeguard its people you have medicine to cure illness, rather than completely according to the purchasing power of people and have no money to heal people to give up its for even the most basic health right, of course, according to people's buying power to get this is one aspect of medical resources, the high purchasing power can enjoy costly medical services. Speaking of which, may be some people think that social medical resources is too limited, not universal. But the society with its maximum capacity, meet the most basic medical needs, the vulnerable groups here are reflected in the field of medical and health care to "fair priority, and also give consideration to efficiency".

\section{REFERENCES}

[1] Yan Gao, Shengqun Wang, Dapeng Cong. Research on Home-based Aged-care Service System in Collaborative City[A]. Proceedings of 2016 International Conference on Contemporary Education, Social Sciences and Humanities (ICCESSH 2016)[C]. 2016

[2] Yu Wang, Qing Tu, Qin Lai, Li Huang. Fairness or Not? Health Resources Allocation in Chongqing-Based on Theil Index[A]. Proceedings of the 9th International Conference on Management and Service Science (MASS 2015)[C]. 2015

[3] Fang Qingwei. Research on Health Human Resources of the Forest Industry Region in Heilongjiang Province Based on SWOT Analysis[A]. Proceedings of 2011 International Conference on Fuzzy Systems and Neural Computing (FSNC 2011 V2)[C]. 2011

[4] Yanhua. Analysis and Evaluation of Degree of Satisfaction of New Rural Cooperative Medical Treatment in Harbin [A]. Proceedings of 2011 International Conference on Applied Social Science(ICASS 2011 V1)[C]. 2011

[5] Ying Chen, Lin Chen, Qiangqing Wang, Xiaosi Xu. The Research of Medical Expenditure in China[A]. Education and Management(ISAEBD 2011 CCIS210)[C]. 2011

[6] Tao Chunhai. Research on medical and health accounting and its account system in China[A]. Proceedings of the International Conference on Recent Trends in Materials and Mechanical Engineering(ICRTMME 2011 Part 3)[C]. 2011 
[7] Proceedings of 2011 International Conference on Biomedicine and Engineering(ISBE 2011 V4)[C]. 2011

[8] Yadan Zhang, Chunfang Cai, Xinde Chen. A Study on Equalization of Basic Medical Services in Shanghai Based on Factor Analysis[A] Proceedings of 2014 International Conference on Global Economy,Commerce and Service Science(GECSS 2014 V78)[C]. 2014
[9] Ranjit Singh. Visualization Enables Accomplishment A Systems Response to Global Calls for Reduction of Harm to Patients in Healthcare[A]. Proceedings of 2014 International Conference on Global Economy, Commerce and Service Science(GECSS 2014 V78)[C]. 2014 